\title{
Growing Teratoma Syndrome of the Ovary Showing Three Patterns of Metastasis: A Case Report
}

\author{
Kiyosumi Shibata Hiroaki Kajiyama Fumitaka Kikkawa \\ Department of Obstetrics and Gynecology, Nagoya University Graduate School of \\ Medicine, Nagoya, Japan
}

\section{Key Words}

Growing teratoma syndrome $\cdot$ Immature teratoma $\cdot$ Three patterns of metastasis

\begin{abstract}
Growing teratoma syndrome (GTS) is defined as metastatic masses during or after chemotherapy for germ cell tumors, which contain only mature teratoma components. The peritoneum of the pelvis and abdomen and the retroperitoneum are the most frequent sites of metastasis. We report a case of GTS of the ovary showing three patterns of metastasis: dissemination, lymphogenous metastasis, and hematogenous metastasis. The patient initially presented 5 years ago with a mixed germ cell tumor of the left ovary and positive cytology of ascites. After surgery and chemotherapy, mature teratomas recurred as pelvic peritoneal dissemination, a para-aortic lymph node mass, and a lung mass. Our case highlights the importance of long-term follow-up and a whole-body search. We think that our case is suggestive regarding the mechanism of critical GTS.

(c) 2013 S. Karger AG, Basel
\end{abstract}

\section{Introduction}

Growing teratoma syndrome (GTS) is a metastatic form of a mature teratoma and involves the clinical and radiological enlargement of metastases during or after chemotherapy for malignant germ cell tumors [1]. In many reported cases, GTS occurred at the site of the primary tumor, and the peritoneum of the pelvis and abdomen and the retroperitoneum were the most frequent sites of metastasis [2]. Here, we report a 19-year-old woman with GTS showing three patterns of metastasis: dissemination, lymphogenous metastasis, and hematogenous metastasis. 
Shibata et al.: Growing Teratoma Syndrome of the Ovary Showing Three Patterns of Metastasis: A Case Report

\section{Case Report}

A 14-year-old girl presented to a local hospital in June 2006 with abdominal fullness. Physical examination was normal except for abdominal discomfort. Computed tomography (CT) scans revealed a $15-\mathrm{cm}$ mass and a small amount of ascites, but no sign of lymph node enlargement (fig. 1). Serum tumor markers were slightly elevated: CA19-9 $=113.8 \mathrm{U} / \mathrm{ml}$, CA125 $=60 \mathrm{U} / \mathrm{ml}, \mathrm{SCC}=2.5 \mathrm{ng} / \mathrm{ml}$, and $\alpha$-fetoprotein (AFP) $=297.4 \mathrm{IU} / \mathrm{ml}$. Serum human chorionic gonadotropin (HCG) was negative. Liver and renal function tests, electrolytes, and a complete blood count were all normal. The initial laparotomy revealed that the left ovary was larger than the size of a child's head and had already ruptured with slightly bloody fluid in the pelvic cavity. Left salpingo-oophorectomy and omentectomy were performed. The cytologic examination of ascites detected malignant cells. Histological examination revealed the tumor to be a mixed germ cell tumor which included a grade 3 immature teratoma (75\%), mature teratoma (10\%), embryonal carcinoma (10\%), and yolk sac tumor (5\%) (fig. 2 ). The patient was therefore diagnosed with a left ovarian mixed germ cell tumor, clinical stage 1c [pT1c(2) NxMx].

She underwent 6 cycles of chemotherapy postoperatively with cisplatin, etoposide, and bleomycin (BEP). The tumor markers normalized 1 month after the operation. Five years after the completion of chemotherapy, routine CT scans revealed dissemination in the pelvic region, para-aortic lymph node metastasis, and lung metastasis (fig. 3). However, the interval since the last examination had been 18 months based on the patient's wishes. No tumor marker was elevated.

The patient was admitted to Nagoya University Hospital for resection of the three types of metastatic mass. Secondary laparotomy showed a 3-cm dissemination on the mesentery of the sigmoid colon and two 1-cm disseminations on the posterior uterus. We removed the three disseminated lesions. Next, we removed an 8-cm metastatic tumor in the para-aortic lymph node. One month after the secondary laparotomy, video-assisted thoracoscopic surgery was performed for a right lung metastasis. Pathologic analysis of the resected specimens revealed that all metastatic tumors were mature teratomas (fig. 4). The patient is now undergoing regular follow-up and remains disease free 11 months after the second surgery.

\section{Discussion}

Logothetis et al. [3] described GTS as an increase in tumor size in a patient with a germ cell tumor either during or after chemotherapy, while the histology showed only mature teratoma and the initial tumor markers were normal.

The mechanism of pathogenesis of GTS remains unclear. Two different mechanisms have been proposed. The first is that chemotherapy induces a selective exclusion of immature components, whereas mature components, resistant to chemotherapy, persist and grow alone as GTS. The second is that chemotherapy influences the differentiation potency and induces the malignant cell differentiation of an immature into a mature teratoma. DiSaia et al. [4] first described the chemotherapeutic retroconversion of germ cell tumors of the ovary. Recently, Amsalem et al. [1] concluded that GTS and chemotherapeutic retroconversion were probably the same phenomenon.

In many cases, GTS nodules exist in the pelvis, abdomen, or retroperitoneum. Only one group reported an ovarian GTS patient with GTS nodules in the neck lymph nodes and lungs [5]. In our case, there were three metastases in the peritoneum, para-aortic lymph node, and 
lung. Para-aortic lymph node and lung metastases were not detected during the initial treatment. In our case, considering the above progress, the second hypothesis is reasonable; however, the possible existence of micrometastases cannot be denied.

The time of GTS onset was within 5 years in most cases, in some cases exceeding 5 years [6]. In our case, the time of GTS onset was 67 months after the adjuvant chemotherapy. Therefore, long-term follow-up is necessary to detect GTS. Regarding sites of recurrence, the peritoneum, lymph nodes, liver, and lungs have been reported $[2,5,6]$. In our case, the patient had three metastases in the peritoneum, para-aortic lymph node, and lung. The case is rare as she showed three patterns (dissemination, lymphogenous metastasis, and hematogenous metastasis), and this is the first report of GTS showing three simultaneous patterns of metastasis.

Surgical resection is recommended for initial treatment because growing tumors apply pressure on surrounding organs and possibly include malignant parts, caused by malignant transformation [7]. Malignant transformation could be to a sarcoma, adenocarcinoma, or a primitive neuroectodermal tumor [8,9] and carcinoid [10].

Considering the surgical procedure, laparoscopic surgery is an option in the case of a small tumor [11]. However, in many cases, surgery was selected based on the tumor size and spread. In our case, the interval between examinations was 18 months. For early detection, examination of the whole body using magnetic resonance imaging and CT is needed. Previous studies revealed 1 patient with GTS who showed a positive fluorodeoxyglucose positron emission tomography (FDG-PET) uptake [5, 12]. In our case, the uptake was negative. More examinations are needed for early detection and treatment.

Here, we report the first case of ovarian GTS with three patterns of metastasis: dissemination, lymphogenous metastasis, and hematogenous metastasis. Our case highlights the importance of long-term follow-up and a whole-body search. We think that our case is suggestive regarding the mechanism of critical GTS.

\section{Acknowledgement}

We acknowledge Dr. Kotaro Sakai for providing the photograph of the abdominal CT.

\section{Disclosure Statement}

The authors declare that they have no conflicts of interest.

\section{References}

1 Amsalem H, Nadjari M, Prus D, Hiller N, Benshushan A: Growing teratoma syndrome vs. chemotherapeutic retroconversion: case report and review of the literature. Gynecol Oncol 2004;92:357-360.

2 Zagame L, Pautier P, Duvillard P, Castaigne D, Patte C, Lhommé C: Growing teratoma syndrome after ovarian germ cell tumors. Obstet Gynecol 2006;108:509-514.

3 Logothetis CJ, Samuels ML, Trindade A, Johnson DE: The growing teratoma syndrome. Cancer 1982;50:1629-1635.

4 DiSaia PJ, Saltz A, Kagan AR, Morrow CP: Chemotherapeutic retroconversion of immature teratoma of the ovary. Obstet Gynecol 1977;49:346-350.

-5 Hariprasad R, Kumar L, Janga D, Kumar S, Vijayaraghavan M: Growing teratoma syndrome of ovary. Int J Clin Oncol 2008;13:83-87.

6 Geisler JP, Goulet R, Foster RS, Sutton GP: Growing teratoma syndrome after chemotherapy for germ cell tumors of the ovary. Obstet Gynecol 1994;84:719-721. 


\section{Case Reports in Oncology}

\begin{tabular}{l|l}
\hline Case Rep Oncol 2013;6:544-549 & \\
\hline DOI: $10.1159 / 000356563$ & $\begin{array}{l}\text { ○ 2013 S. Karger AG, Basel } \\
\text { www.karger.com/cro }\end{array}$ \\
\hline
\end{tabular}

Shibata et al.: Growing Teratoma Syndrome of the Ovary Showing Three Patterns of Metastasis: A Case Report

7 André F, Fizazi K, Culine S, Droz J, Taupin P, Lhommé C, Terrier-Lacombe M, Théodore C: The growing teratoma syndrome: results of therapy and long-term follow-up of 33 patients. Eur J Cancer 2000;36:13891394.

8 Jumean HG, Komorowski R, Mahvi D, Anderson T: Immature teratoma of the ovary - an unusual case. Gynecol Oncol 1992;46:111-114.

-9 Ahlgren AD, Simrell CR, Triche T, Ozols R, Barsky SH: Sarcoma arising in a residual testicular teratoma after cytoreductive chemotherapy. Cancer 1984;54:2015-2018.

-10 Djordjevic B, Euscher ED, Malpica A: Growing teratoma syndrome of the ovary: review of literature and first report of a carcinoid tumor arising in a growing teratoma of the ovary. Am J Surg Pathol 2007;31:19131918.

11 Matsushita H, Arai K, Fukase M, Takayanagi T, Ikarashi H: Growing teratoma syndrome of the ovary after fertility-sparing surgery and successful pregnancy. Gynecol Obstet Invest 2010;69:221-223.

12 Kikawa S, Toda Y, Minobe S, Yamashiro K, Kato H, Sakuragi N: Growing teratoma syndrome of the ovary: a case report with FDG-PET findings. J Obstet Gynaecol Res 2011;37:926-932.

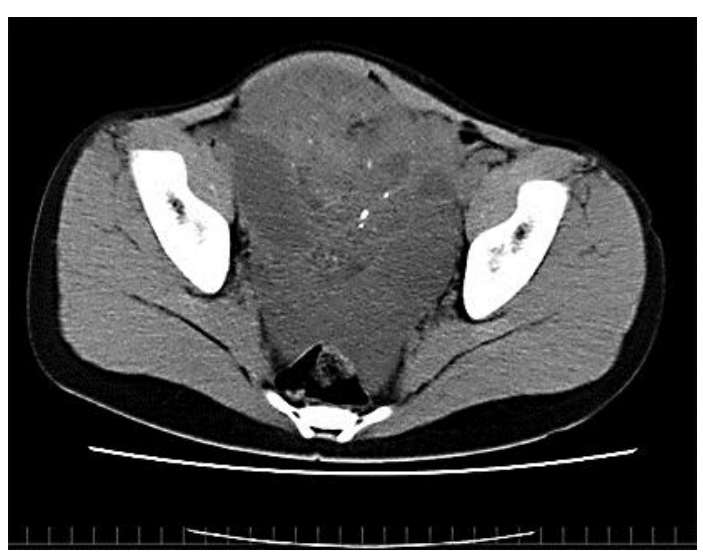

Fig. 1. CT findings of primary tumors.

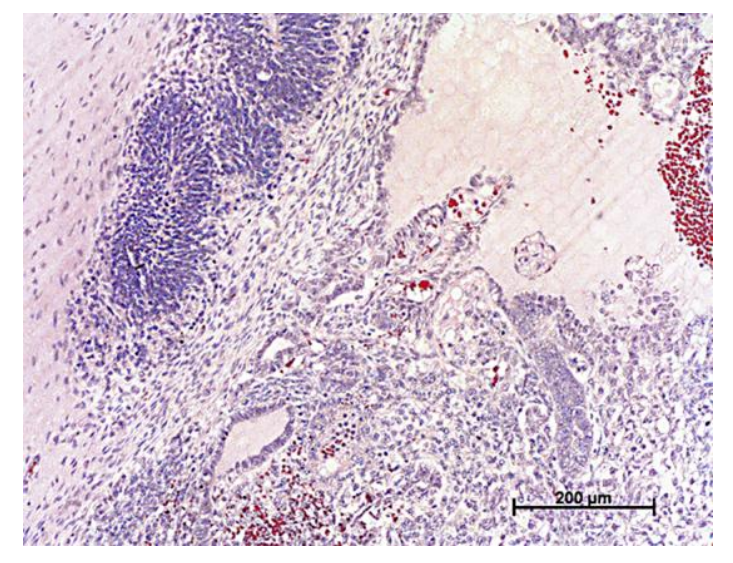

Fig. 2. Histological features of primary tumors. Histological examination revealed the tumor to be a mixed germ cell tumor which included a grade 3 immature teratoma, mature teratoma, embryonal carcinoma, and yolk sac tumor. 


\section{Case Reports in Oncology}

\begin{tabular}{l|l}
\hline \multicolumn{2}{l}{ Case Rep Oncol 2013;6:544-549 } \\
\hline DOI: 10.1159/000356563 & $\begin{array}{l}\text { C 2013 S. Karger AG, Basel } \\
\text { www.karger.com/cro }\end{array}$ \\
\hline
\end{tabular}

Shibata et al.: Growing Teratoma Syndrome of the Ovary Showing Three Patterns of Metastasis: A Case Report
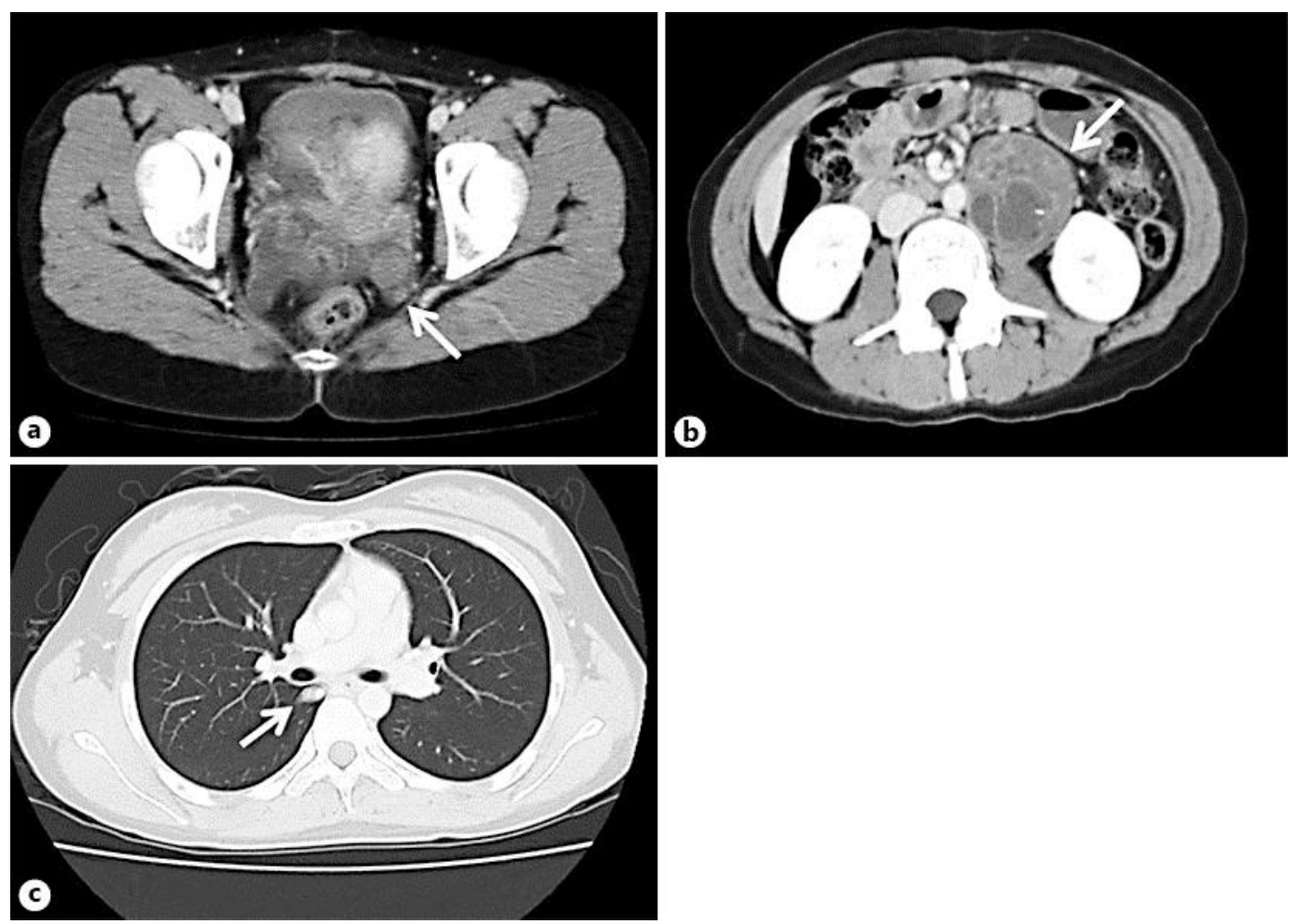

Fig. 3. CT findings of three sites of tumor recurrence. The recurrent tumors are indicated by white arrows. a The appearance of a recurrent tumor of pelvic dissemination. $\mathbf{b}$ The appearance of a recurrent tumor of the para-aortic lymph node. $c$ The appearance of a recurrent tumor of the lung. 

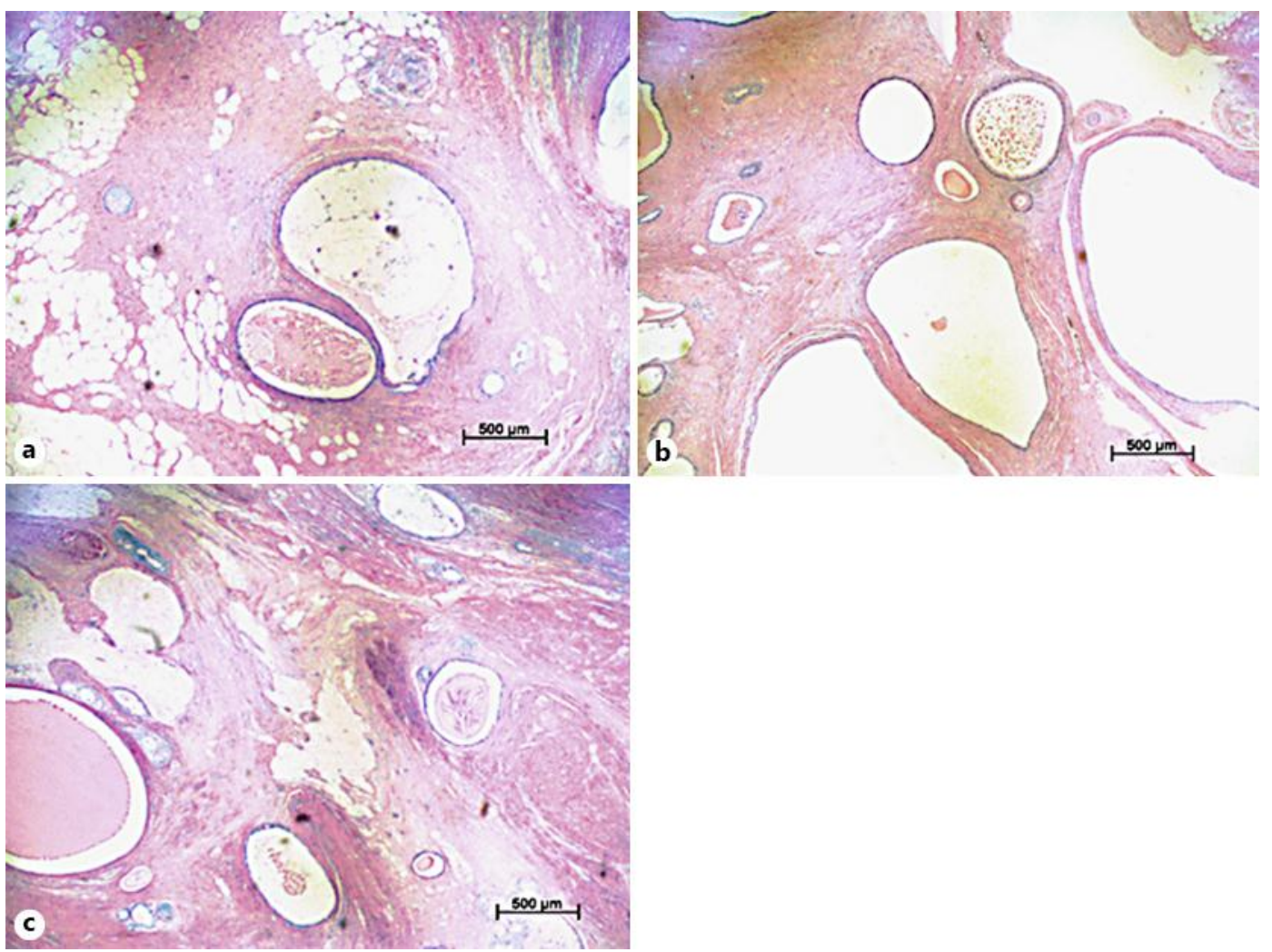

Fig. 4. Histological features of recurrent tumors. Mature glandular tissue was seen in the recurrent, new mass, but no immature tissue was identified (HE, $\times 100)$. a Pelvic dissemination. b Para-aortic lymph node metastasis. c Lung metastasis. 